\title{
People choice modelling for evacuation of tall buildings
}

Mitko Aleksandrov ${ }^{a}$, Abbas Rajabifard $^{a}$, Mohsen Kalantari ${ }^{a}$, Dr. Ruggiero Lovreglio ${ }^{b}$ and, Dr. Vicente A. González

a) The University of Melbourne, Center for Disaster Management and Public Safety, Department of Infrastructure Engineering, Parkville VIC 3010, Australia

b) The University of Auckland, Civil and Environmental Engineering, Faculty of Engineering, Auckland, 1010, New Zealand

Prof. Abbas Rajabifard - abbas.r@unimelb.edu.au

Dr. Mohsen Kalantari - mohsen.kalantari@unimelb.edu.au

Dr. Ruggiero Lovreglio - r.lovreglio@auckland.ac.nz

Dr. Vicente A. González - v.gonzalez@auckland.ac.nz

Corresponding Author:

Mitko Aleksandrov

Center for Disaster Management and Public Safety

Parkville VIC 3010, Australia

Walter Boas, 405

Email: mitko.aleksandrov@unimelb.edu.au 


\title{
People choice modelling for evacuation of tall buildings
}

\begin{abstract}
Modelling people behaviour during emergencies has become an essential issue in attempting to increase safety aspects in buildings. This paper evaluates people's choice behaviour for evacuation of tall buildings. A Stated Preference (SP) questionnaire was designed to understand underlying factors behind people behaviour and predict the likelihood of selecting evacuation lifts as opposed to stairs. Various scenarios including 6 different navigational cases, 3 levels for the density of people on stairs, 3 different number of people in the lift lobby and 3 vertical positions for refuge floors were administrated to 566 participants. A mixed logit model approach was then used to investigate how those factors influence the occupant's decision-making as well as to capture the heterogeneity of different preferences among people. Traditionally, lifts were not allowed to be used in case of emergency, but the results indicate that people would tend to choose evacuation lifts in situations when they are suggested as the main exit option, and situations when stairs are overcrowded. Thus, if people are navigated by dynamic signs to use evacuation lifts, the percentage of lift users could go approximately from $70 \%$ to $80 \%$ for refuge floors between 15 and 55 , respectively. In contrast, in situations when people have to make a decision between using lifts or stairs to evacuate, stairwells with fewer people as well as overcrowded refuge floors could lead to a decision in favour of stairs. This study represents the first SP experiment combining people decisions, pre-event opinions and beliefs related to evacuation lifts and stairs to understand their route choices for evacuation from tall buildings. The findings of this study can be used in the development of behavioural models for evacuation simulations of tall buildings.
\end{abstract}

Keywords: Evacuation, Human Behaviour, Refuge floors, Evacuation lifts, Tall buildings

\section{Introduction}

Tall and supertall buildings possess specific challenges in terms of egress design, since evacuation by stairways can indicate going down hundreds of flights of stairs. The egress design and relocation strategy of tall buildings are the main challenges for building designers [1-2]. A possible solution using evacuation lifts for evacuation of tall buildings was suggested [3]. Currently, there are two strategies that involve using lifts for evacuation of tall buildings. In the first, evacuation lifts serve the fire floor, and one level above and below it, while the second combines stairs, refuge floors and evacuation lifts [4]. However, the main issue with the former approach is that it does not provide an option for total evacuation of the building. Such an approach could cause many people to wait for the same lifts on many floors, increasing the waiting time for lifts and causing more people to redirect towards stairs. As a result, researchers suggest combining stairs, refuge floors and evacuation lifts to achieve safe and fast evacuation [5], which is also evident in many tall buildings having implemented this strategy [6].

Refuge floors are currently required in all high-rise buildings in the Middle East and Asia to ensure a place of temporary refuge, where people could have a short rest as well as an option to cross over between stairways. The frequency of placing refuge floors is between 15 and 30 floors depending on occupancy [7]. However, researchers doubt the practicality of refuge floors [8]. Although during evacuation drills, it is reported that people tend to follow directions of a chief warden and evacuate to the nearest refuge floor. The primary concern is overcrowding of refuge floors, which may cause people to redirect towards stairs and impede egress flow [4]. 
The main reason for not using lifts in case of emergency is historical guidance presented to the public over last decades by the emergency management community: "In case of fire, do not use lifts". Thus, it results in an inability to predict public reaction to the use of lifts for evacuation purposes. In this regard, some questions have been raised in the fire safety community: Would people want to use lifts for evacuation from tall buildings? What would be the percentage of lift users? [4]. Evacuations of Petronas Towers the day after 9/11 attacks highlighted this challenge, where people did not want to wait for lifts but redirected towards stairs, which prolonged the evacuation process significantly [9]. Underlying factors behind people decisions arising from their pre-event opinions or beliefs about a particular disaster which can result in actions that should be taken into account well before the disaster occurs [10]. Research shows that the next course of people's action strongly depends on their preferences, where a "rational" choice will take place by weighing all available options and select an option that $s /$ he perceives as a sufficient rather than optimal [11-12]. Also, significant time pressure resulting from crisis or uncertainty can encourage people to search for more options [13-14]. This was the case during the 9/11 incident, in which people tried to use lifts although they were not available for evacuation [15]. Hence, differences in people behaviour should be investigated to predict the outcome of possible evacuation scenarios and reduce adverse effects that can occur during a disaster [10]. This is done in this paper by collecting data using a stated preference survey and by analysing it using the random utility theory. This theory and related models (i.e. random utility models) represent one of the main approaches used nowadays to investigate and model evacuees facing discrete choices (e.g. take the lift or take the stairs). Pros and cons of using this modelling approach and a comparison with other approaches (e.g. fuzzy theory and game theory) is available in [16-17].

Random utility models (RUMs) describe decision makers' choices among a finite number of mutually exclusive alternatives [18]. In fact, RUMs allow the researcher not to observe the decision maker's utility in our case utility to choose an alternative related to stairs or lifts, but to observe some attributes of the alternatives faced by the occupant, and characteristics related to the occupant that affect the utility. Thus, a function that relates these observed factors to the utility of the occupant is specified. Another advantage of these models is the inclusion of systematic and random preferences of the decision maker [19]. To date, RUMs have been successfully applied in many areas such as marketing [20], finance [21] and transport [19-20]. Finally, RUMs have been applied to investigate how people make route and exit choice [21-25]. Those studies show how mixed logit models are valuable tools to investigate preference heterogeneity among the population. In this paper, mixed logit model has been adopted to model the importance of factors which may affect people's choices to use stairs or evacuation lifts for evacuation of tall buildings.

The main contributions of the paper are: firstly, the collection of stated preferences to investigate the impact of several environmental, social and personal factors; secondly, the investigation of people behaviour considering the systematic and random preferences of decision makers, using the mixed logit model. The paper is structured in five main parts. The first part paper provides insight into the current knowledge of possible people behaviours for evacuation of tall buildings. The second part explains the methodology used in the paper. The third part describes the experimental design. The fourth part explains the application of the mixed logit model and the main findings. The final part ends with the research conclusions and future directions, which are required to predict people behaviour for evacuation of tall buildings.

\section{Background}

So far 5 hypothetical experiments were conducted by researchers to investigate and to model people behaviour for evacuation of tall buildings considering lifts and stairs as available egress options. To have a better insight into the differences of the experiments' assumptions and limitations a detailed description of them is provided in Table 1. The cross comparison suggests that experiments used various data collection techniques. Although field experiments that required people's physical presence such as field experiments and virtual reality experiments have the highest ecological validity, they achieved lower people participation. Sociodemographic characteristics between studies were similar, having mostly young people as participants. 
When it comes to factors that may affect people's decisions, it is important to predict whether a person would stay or redirect towards the stairs considering the absolute vertical position of refuge floors in the building as well as the overcrowding level of the lift lobby [29]. Waiting time can be collected; however, since it is not estimated and presented to people during the decision-making process, people usually cannot predict their maximum waiting time correctly [30], and even if collected the scatter of results is high [5]. Nevertheless, there is no research yet assessing how the density of people on stairs influences the people decisions, which was the primary reason of people stopping or switching to other stairs a number of times during 9/11 attacks [31]. Research also suggests that people would follow a recommended route if it is specified [8], [32]. Another disadvantage of the available research is using cumulative probability instead of discrete choice models to estimate the impact of each individual parameter on the output.

Therefore, the impact of the density of people on stairs, the number of people in front of lifts and the vertical position of refuge floors were tested on people's decisions in this paper. In addition, different navigational scenarios were tested to understand to what extent messaging strategy and social influence can impact decisions of people to select evacuation lifts for the evacuation of tall buildings.

\section{Methodology}

The design methodology for the SP survey is motivated by [33]. All steps can be summarised in 3 main stages: background, survey design and data collection and modelling (Figure 1).

The first step represents identifying objectives and relevant variables that will be tested in the questionnaire by conducting an extensive state-of-the-art bibliographic review. After selecting initial parameters related to specific objectives, a preliminary questionnaire is designed and tested using focus group techniques. Focus groups were formed from students who either have or do not often have interactions with high-rise buildings. People who were part of focus groups did not participate afterwards in the questionnaire. The iterative process between preliminary versions of the questionnaire and focus groups resulted in the final parameters tested in the questionnaire's scenarios. The third step involves finding the optimal model considering the results given by the participants using discrete choice models.

\section{Experimental design}

To understand the relative importance of the underlying factors that may influence people's decisions for evacuation of tall buildings an online questionnaire was conducted between August 2016 and November 2016. Participants were asked to predict how they would behave in different situations and positions in the building. The questionnaire was distributed among students at the University of Melbourne and sent to building managers of the tallest buildings in Melbourne to distribute the questionnaire to their residents. The main reason why Australia was selected is a proposal to building designers by Australian Building Code Board to start considering the implementation of evacuation lifts in tall buildings [34]. The questionnaire includes five main parts. The first part provides general information on the building evacuation design, evacuation procedure and scenarios. The second part contains three case studies that evaluate the impact of different factors on the behavioural model of people for evacuation of tall buildings. The third provides insight into characteristics of participants as well as possible limitations of the research. The fourth part describes the limitations of the research. The fifth part presents the model specification used in the paper.

\subsection{Building evacuation design and procedure}

In the questionnaire, a 75-story building has been considered containing 3 refuge floors located on floor 15, 35 and 55. In the paper, a $112 \mathrm{~mm}$ standardised stair was tested, whose characteristics are defined in line with NFPA 101 [35]. The building has 3 evacuation lifts which is the number of lifts integrated into the building evacuation design of the tallest building in Melbourne - Eureka Tower [36]. At the beginning of the questionnaire, a brief introduction of the evacuation procedure, the building evacuation design and the 
purpose of refuge floors was explained to the participants. However, it is worth mentioning that being familiar with the building evacuation design and procedure may have a different impact on the occupant's decision, which could enhance the performance of the evacuation procedure [37].

It was explained to the participants that the evacuation procedure requires going downstairs to a refuge floor, where participants would need to decide whether to continue evacuating via stairs or to take evacuation lifts to the ground floor. Questions in the questionnaire were presented in a sequential order reflecting the order that people would experience the conditions/choices during an evacuation. The description of the building evacuation design, scenarios and case studies tested are presented in Figure 2.

\subsection{The case studies}

People behaviour during evacuations can vary from highly predictable with less uncertainty to hardly predictable with huge uncertainty. Research argues that actions are more likely to be predictable and certain if the number of choices is fewer, people have experienced the procedure before and it is not something new for them [38]. Hence, since evacuation by lifts is not usually a standard egress option for evacuation which increases the number of alternatives by including them, it is more likely to have a higher level of uncertainty between alternatives. In this research, scenarios suggesting evacuation lifts as the main egress option as well as a preferred choice of escape route are tested to understand whether reducing the number of options would lead to lower uncertainty. Research also shows that providing real-time information impacts a person's decisions, beliefs and behaviour [36-37], which also was investigated in the paper.

Different navigational scenarios were presented to the participants, together with videos showing evacuations with different density levels of people on stairs and a different number of people in front of lifts. The density of people on stairs was considered as a parameter which is independent on the type of stairs. Duration of videos was between 20 and 30 seconds, and they were created using Pathfinder simulator [41].

Three case studies are presented to the participant considering various aspects (Table 2). The first case study investigated what the outcome would be in a situation when the participant is in his/her room. The second considered a situation when $\mathrm{s} / \mathrm{he}$ is on the stairs approaching the refuge floor, whereas the third one represented a case when the participant arrived at the refuge floor.

Regarding the third case study, two models are presented in the paper. The first model integrated the decision when the participant was on stairs to understand if people would stick to their previous choice when they come to the refuge floor, while the second model considered these two processes separately. The main objective is to understand whether people would stick to their previous choices. If this is the case, it would mean that there is no need for people who prefer stairs for evacuation to come to the lift lobby and wait for lifts, since they would choose stairs anyway.

\subsubsection{Navigational scenarios evaluation}

During their trip to evacuate the building, people needed to decide whether to go to a refuge floor to use evacuation lifts or to continue their evacuation via stairs. Six navigational scenarios were presented to the participants, namely going alone, going with family, going with familiar or unfamiliar people that decided to use evacuation lifts, and scenarios when a responsible person or dynamic signs advised people to use evacuation lifts as a first option (see Figure 3). Participants needed to predict their intended behaviour for each evacuation scenario considering the position of 3 refuge floors (15, 35 and 55 floor). Thus, participants were tested in 18 ( 6 scenarios $\times 3$ refuge floors) hypothetical choice scenarios.

\subsubsection{Choosing lifts or stairs under uncertainty}

The going alone evacuation scenario (i.e. the scenario where participants are asked to evacuate without a personal group) is taken into account to represent an evacuation scenario under uncertainty when people are not advised which way to take, having the freedom to choose between both egress options. Going alone scenarios were only tested in the questionnaire so as to keep participants in the proposed time for completing the questionnaire. 
The density level on stairs in high-rise buildings can usually go from 0 person $/ \mathrm{m}^{2}$ (empty stairs) to 3.8 persons $/ \mathrm{m}^{2}$ (people stop moving). In order to predict how density of people on stairs can influence decisions to use evacuation lifts or stairs, three density levels of people on stairs $\left(1,2\right.$ and 3 persons $\left./ \mathrm{m}^{2}\right)$ were investigated, shown in Figure 4. Participants needed to predict their intended behaviour for each evacuation scenario while considering the position of 3 refuge floors (15, 35 and 55 floor), which resulted in 9 hypothetical choice scenarios.

\subsubsection{Waiting for lifts or backing up to stairs under uncertainty}

Once people arrived at a refuge floor, an occupant was supposed to decide whether to stay and wait for lifts or redirect towards stairs. Building designers should predict the likelihood of people selecting evacuation lifts in order to calculate the demand for evacuation lifts. In this regard, the importance of several parameters (vertical position of refuge floors, number of people in the lift lobby, density on stairs and the previous choice of people) were tested. Even though when people come to a refuge floor they do not have insight into the current density of people on stairs, the density level was presented to the participants since they would come from the stairs to the refuge floor. The previous choice of people is considered to understand if there is a difference among decisions of people who have not chosen to come to refuge floors and those who decided to come considering the density on stairs from the previous model.

The total number of possible scenarios was 27 ( 3 densities on stairs scenarios $\left(1,2\right.$ and 3 persons $/ \mathrm{m}^{2}$ ) $\times 3$ scenarios with a different number of people in front of lifts (50, 100 and 150 people) x 3 refuge floors (15, 35 and 55 floor)). The selection of people's number in front of lifts is based on the study done by [29].

Since the number of scenarios is 27 , a double-bounded contingent valuation method is used to present a fewer number of scenarios to the participants [41-42]. This method takes into account the respondent's answer to the previous question in order to present the next question (Figure 5). Thus, participants needed to predict their intended behaviour for a minimum of 12 scenarios and a maximum of 27 scenarios. As a starting scenario, a case with 2 persons $/ \mathrm{m}^{2}$ for people on stairs and 100 people in front of lifts was selected (Figure 6).

\subsubsection{Understanding underlying factors behind people's choices}

After answering these questions, participants are asked to provide what were the main reasons for choosing stairs or lifts for evacuation purposes in several aspects depending on position of refuge floors: quicker way, safer way, level of control when using stairs and lifts, escaping the crowd in front of lifts and stairs, knowing that lifts cannot be used for evacuation, allowing others to use lifts, concern about waiting time for lifts, concern about the programming of the lift, concern about physical fitness. The impact of these factors was taken into account in all models.

\subsection{Respondents}

A total of 566 participants conducted the experiments. People who live, work or study in Melbourne participated in the questionnaire. Participants were asked to provide information on their age, gender, physical activity level, height, weight, the connection type with high-rise buildings (living, working, visiting or no connection). Characteristics of respondents are presented in Table 3.

\subsection{Limitations}

It should be acknowledged that there are some limitations with SP experiments in predicting people's behaviour, which may jeopardise the ecological validity of the results. Thus, there are four main drawbacks which are identified.

The first relates to the shortage of details available and that not all people can mentally put themselves into the situation without physically witnessing it. Moreover, even if people acquire a good understanding of the situation, a behavioural intention questionnaire cannot adequately provide first-hand insight into the physical and social environment [10]. Thus, a person cannot perceive the movement of the simulated agents as opposed to real people movement due to the low level of behavioural realism [44]. 
The second drawback is hypothetical experiments result in people being aware of their involvement in a trial anticipate their choice in the hypothetical situation as opposed to decisions made in a real emergency [12]. However, new research shows that estimated patterns related to parameters show consistency regardless of coming from stated or revealed preferences experiments [28].

The third implies that newly developed models coming from SP experiments should be validated to be used for practical purposes and designer projects [45].

The fourth states that the familiarity with the evacuation procedure and environment can impact decisions of people, which could enhance the performance of the evacuation procedure [37].

\subsection{Model specification}

To quantify the impact of each variable that influences participants' decisions, a mixed logit model is used. The utility that the decision maker $n(n=1,2, \ldots N=566)$ obtains from alternative $j(j=$ stair, elevator $)$ in choice situation $t(t=1,2, \ldots, T)$ is calculated by equation 1 , where $X_{n j t}$ represents the vector of observed variables related to the alternative and the decision maker, $\beta$ is the vector of utility coefficients associated to those variables, and the unobserved portion of utility $\varepsilon_{n j t}$ which is assumed to be independent over $n, j$ and $t$. Thus, the choice probabilities can be expressed using equation 2 .

$$
\begin{aligned}
& U_{n j t}=\beta^{T} X_{n j t}+\varepsilon_{n j t} \\
& P_{n i t}=\int\left(\frac{e^{\beta^{T} X_{n i t}}}{\sum_{j} e^{\beta^{T} X_{n j t}}}\right) f(\beta) d \beta
\end{aligned}
$$

A number of 1000 Halton draws are used to assure that simulation error in the estimated parameters is low [46]. Also, panel data is included to increase the degree of freedom of the model considering the correlation between replies of individuals for different scenarios, since the impact of factors that are not observed can persist over time [18]. Mlogit package for R programming language is used to obtain the variables' coefficients [47]. All independent variables included in the model are assumed to have a random normal distribution. The main reason for assuming normal distribution is the fact that standard deviation of the parameters is most likely distributed equally around mean value, and there is not a specific reason why it would take an asymmetric shape of any other known distribution type. All models were tested including full models that have statistically higher fit compared to the presented models, which contain a lower number of parameters. In order to test this assumption, likelihood ratio test was used, which compares the likelihood of the data under the full model against the likelihood of the data under a model with fewer parameters [48]. All four presented models were examined, resulting in the conclusion that full models do not perform better than the proposed models showing that excluded parameters were not statistically significant to be included in the model.

\section{Results}

The experimental design for the case studies resulted in 4 models, which highlight the impact of different factors on people's behaviour, in order to select evacuation lifts/stairs for evacuation in tall buildings. The importance of the navigation strategy (i.e. free choice between alternatives and suggesting to choose a particular alternative) and social influence was tested in model 1, whereas model 2 estimates the impact of density of people on stairs and position of the refuge floor on a person at the refuge floor to decide whether to switch between stairs or to go to the lift lobby and wait for evacuation lifts. The impact of the vertical position of refuge floors, the density of people on stairs, the number of people in the lift lobby and the previous choice were considered in the model 3. Model 4 investigated a situation where all people would needed to come first to the lift lobby at the refuge floor to decide between waiting for evacuation lifts and stairs.

All models' estimations are followed by a sensitivity analysis of the models to understand better the possible behaviours for evacuation of tall buildings, which quantifies how the uncertainty in the output of the model is distributed over input parameters for choosing a particular egress option. Thus, it is evaluated how 
changes in factors may impact and to what extent the decision-maker to choose evacuation lifts or stairs for evacuation of tall buildings.

The estimation parameters for model 1, which refers to navigational scenarios evaluation, are presented in Table 4. Variable included in the model depends on a scenario under consideration (going with family, going with familiar and unfamiliar people that decided to take evacuation lifts, navigation with the help of a responsible person and dynamic signs), vertical position of refuge floors, factors referring to occupant's belief (knowing the fact that lifts cannot be used for evacuation, seeing stairs as a safer and quicker way, trying to escape the crowd in front of lifts), a factor which is related to the physical health of the occupant (multiplication of occupant's BMI, level of fitness and concern about physical fitness $\mathrm{BMI}^{*}$ FitnessLevel*Concern), and a variable which refers to the alternative specific constant (ASC). It can be inferred from the model that coefficients of all parameters are statistically significant at more than $99.9 \%$ confidence interval. The statistical significance of standard deviation of included variables confirmed the presence of preference heterogeneity over the population.

Table 5 shows that the best performance in terms of the percentage of lift users is achieved by dynamic signs indicating to use evacuation lifts for evacuation. The range of lift users goes approximately from $70 \%$ to $80 \%$ for floors between 15 and 55, respectively. The same navigational strategy considering a responsible person advising people to use evacuation lifts accomplished slightly lower percentage of lift users, resulting in the fact that people are more willing to follow and obey evacuation instructions coming from dynamic evacuation signs than by staff. The sensitivity analysis shows that the position of the refuge floor has the least impact on a person's decision to choose evacuation lifts considering those two scenarios. Thus, the assumption that reducing the number of options or suggesting a particular egress component for evacuation led to a solution with less uncertainty. On the other hand, other evacuation scenarios tested in the questionnaire strongly depend on the position of refuge floors and have similar trends between each other (see Figure 7). Results also suggest that people would follow each other, showing that herding behaviour would be evident for scenarios when a person was accompanied by known or unknown people, compared to the scenario when the person was going alone. At the same time when a person needed to make the decision for their family, they tended to choose evacuation lifts more often in comparison to the scenario when they were alone.

Table 6 shows that the estimation parameters related to the density of people on stairs, the position of refuge floors, knowing the fact that lifts cannot be used for evacuation, BMI*FitnessLevel*Concern, seeing stairs as a safer way and seeing lifts as quicker way and ASC, which were included in model 2, are statistically significant. Parameters distribution confirmed the presence of preference heterogeneity among decisions of people as well.

Table 7 shows two models considering both building configurations. Model 3 shows the difference between people who would decide to observe the situation at a lift lobby and those who would switch between stairs at the refuge floor, whereas model 4 integrates decisions of all people. Both models indicated that the position of refuge floors, the density on stairs, and the number of people in front of lifts highly influence the decision to select evacuation lifts or stairs for evacuation. People were also committed to their previous choice, and thus people that would like to go to the lift lobby would more likely stick to their initial choice and wait for evacuation lifts and vice versa. The coefficient associated with a number of people in front of lifts was not randomly ${ }^{1}$ distributed in both models, compared to other parameters' coefficients.

Table 8 shows sensitivity analysis for model 3 considering only people who decided to go to refuge floors and model 4 includes all responses of people. In both of the cases, the results indicate that people would not choose evacuation lifts if the refuge floor is highly occupied. In contrast, people would stay and wait for evacuation lifts only in a situation when stairs are congested such as a situation having 3 persons $/ \mathrm{m}^{2}$ on stairs. The previous choice played an important role only in situations when the lift lobbies are less overcrowded, which was also the difference between model 3 and 4 (see Figure 8).

\footnotetext{
1 Parameters of a model should be tested to determine the share of participants having either a positive or negative coefficient for a specific parameter. In situations when this share is pretty small, the share should be ignored and the coefficient should be fixed rather than random [18], [47].
} 
Table 9 represents people's perception of the use of stairs and lifts for evacuation purposes, which is drawn from people's pre-event opinions or beliefs. The underlying factors are divided into two groups, one referring to stairs and one referring to lifts. The results suggest that people consider these factors differently depending on the position of refuge floors. The statistical importance of some factors was present in model 1 and 2 , while for model 3 and 4 this was not the case.

\section{Discussion}

The research provides people choice modelling between stairs and evacuation lifts for evacuation of tall buildings. The evaluated evacuation procedure considered using stairs to refuge floors where people needed to decide to either use evacuation lifts or switch between stairs. In this paper, a mixed logit model was adopted to model people's choices probabilistically and allows modelling of different preferences among them. A questionnaire was completed by 566 people to gather data for the model.

The methodology highlighted the influence of some factors participant decisions. Presented models have shown the importance of considering the navigational strategy, the density of people on stairs, the number of people on the lift lobby, the vertical position of refuge floors and the previous choice of people depending on the building configuration. Thus, the research showed the importance of considering a few new aspects such as navigational strategy and density of people on stairs comparing the models with other available models explained in Table 1. Based on model 1, the social impact may have an impact on decision-maker, and it should be considered in the future studies.

The results suggest that people would rather choose evacuation lifts in situations when they are the first option for evacuation and situations when stairs are overcrowded, whereas in situations when people need to make the decision between evacuation lifts and stairs, less crowded stairs and an overcrowded lift lobby lead to a decision in favour of stairs. The results also showed that people would stick with their previous choice, indicating that the next course of action of people is dependent on the previous one. Although the mixed logit model modelled the impact of unobserved factors and factors that refer to people pre-event perception of egress options, further research is required to acquire a full picture about choice modelling of people for evacuation of tall buildings.

\section{Conclusion and future works}

The present paper investigated decision-making process of people highlighting the effectiveness of different evacuation strategies for the evacuation of tall buildings. The paper brought two important findings showing that the uncertainty in people's decisions decreases when suggesting them the preferred means of egress, and the next course of action of people depends on the previous choice and preconception related to alternatives.

The presented models allow the modelling and understanding of possible people behaviours for evacuation of tall buildings. The results presented in the paper can be used as a good starting point for the development of more comprehensive behavioural models. The importance of providing real-time information to people was highlighted in the paper, where navigating people towards evacuation lifts by a responsible person and dynamic signs resulted in navigation strategies with the least uncertainty and the most controlled evacuation process. Therefore, future research to identify an effective evacuation procedure for tall buildings evacuation lifts should be considered as the main exit option.

In this paper, many factors are presented as having possible effects on the decision-maker during the evacuation process of tall buildings. However, in the future, great attention should be placed on the development of a fundamental theory related to occupant's route choice selection between evacuation lifts and stairs for evacuation of tall buildings, considering the findings in order to create more resilient building evacuation designs and evacuation strategies for tall buildings. Another aspect which requires attention would be consideration of the severity of an event on people's decisions. Since refuge floors and evacuation lifts are 
not very common in Australia, the results could be place dependent, which also requires investigating the decision-making of people who are aware of their use. There is a need also to explore building configurations with different heights, stairs and evacuation lifts.

\section{References}

[1] J. Tubbs and B. Meacham, "Selecting appropriate evacuation strategies for super tall buildings: Current challenges and needs," in Proceedings of the 4th International Symposium on Human Behaviour in Fire. Robinson College, Cambridge, 2009, pp. 41-50.

[2] M. Luo and K. H. L. Wong, "Evacuation Strategy for Super Highrise Buildings," in 5th Annual Seminar Tall Building Construction and Maintenance. Hong Kong. , 2006.

[3] R. W. Bukowski, "Emergency egress from ultra tall buildings," in Tall \& Green, Typology for a Sustainable Urban Future, CTBUH, Dubai UAE, 2008, p. 9.

[4] R. W. Bukowski and J. S. Tubbs, "Egress Concepts and Design Approaches BT - SFPE Handbook of Fire Protection Engineering," M. J. Hurley, D. T. Gottuk, J. R. Hall Jr., K. Harada, E. D. Kuligowski, M. Puchovsky, J. L. Torero, J. M. Watts Jr., and C. J. WIECZOREK, Eds. New York, NY: Springer New York, 2016, pp. 2012-2046.

[5] E. Ronchi and D. Nilsson, "Fire evacuation in high-rise buildings: a review of human behaviour and modelling research," Fire Sci. Rev., vol. 2, no. 1, pp. 1-21, 2013.

[6] M. T. Kinateder and E. D. Kuligowski, The use of elevators for evacuation in fire emergencies in international buildings. 2014.

[7] K. Clawson and D. J. O'Connor, "Considerations and Challenges for Refuge Areas in Tall Buildings," in CTBUH 2011 World Conference, 2011, pp. 332-338.

[8] D. Barber and P. Johnson, "Refuge floors - history, implementation and methods for improvement," in Human Behaviour in Fire Proceedings of the 6th International Symposium, 2015, pp. 245-256.

[9] A. Ariff, "Review of Evacuation Procedures for Petronas Twin Towers," in CIB-CTBUH International Conference on Tall Buildings. CIB Publication no: 290, Kuala Lumpur, 2003.

[10] E. D. Kuligowski, "Human behavior in fire," in SFPE Handbook of Fire Protection Engineering, Springer, 2016, pp. 2070-2114.

[11] P. Slovic, B. Fischhoff, and S. Lichtenstein, "Behavioral decision theory," Annu. Rev. Psychol., vol. 28, no. 1, pp. 1-39, 1977.

[12] R. Lovreglio, "Modelling Decision-Making in Fire Evacuation Using Random Utility Theory," Politec. di Bari, Milano Torino, 2016.

[13] D. Zakay, "The impact of time perception processes on decision making under time stress," in Time pressure and stress in human judgment and decision making, Springer, 1993, pp. 59-72.

[14] H. Ben Zur and S. J. Breznitz, "The effect of time pressure on risky choice behavior," Acta Psychol. (Amst)., vol. 47, no. 2, pp. 89-104, 1981.

[15] N. H. Averill JD, Mileti DS, Peacock RD, Kuligowski ED, Groner N, Proulx G, Reneke AP, "Final report on the collapse of the World Trade Center towers. Federal building and fire safety investigation of the World Trade Center disaster, occupant behaviour. Egress and emergency 
communications. September. NIST NCSTAR 1-7. National Institute of St," 2005.

[16] R. Lovreglio, "Modelling Decision-Making in Fire Evacuation based on Random Utility Theory," 2016.

[17] R. Lovreglio, D. Borri, E. Ronchi, A. Fonzone, and L. Dell'Olio, "The need of latent variables for modelling decision-making in evacuation simulations," IX Int. Work. Plan. Eval., Bari, 2015.

[18] K. Train, Discrete choice methods with simulation. Cambridge university press, 2003.

[19] D. McFadden and K. Train, "Mixed MNL models for discrete response," J. Appl. Econom., pp. 447-470, 2000.

[20] M. Ben-Akiva and B. Boccara, "Discrete choice models with latent choice sets," Int. J. Res. Mark., vol. 12, no. 1, pp. 9-24, 1995.

[21] K. A. Small and H. S. Rosen, "Applied welfare economics with discrete choice models," Econom. J. Econom. Soc., pp. 105-130, 1981.

[22] M. E. Ben-Akiva and S. R. Lerman, Discrete choice analysis: theory and application to travel demand, vol. 9. MIT press, 1985.

[23] C. R. Bhat, "Simulation estimation of mixed discrete choice models using randomized and scrambled Halton sequences," Transp. Res. Part B Methodol., vol. 37, no. 9, pp. 837-855, 2003.

[24] R. Lovreglio, D. Borri, L. Dell'Olio, and A. Ibeas, "A discrete choice model based on random utilities for exit choice in emergency evacuations," Saf. Sci., vol. 62, pp. 418-426, 2014.

[25] R. Lovreglio, A. Fonzone, and L. Dell'Olio, "A Mixed Logit Model for Predicting Exit Choice During Building Evacuations," Transp. Res. Part A, 2016.

[26] R. Lovreglio, A. Fonzone, L. Dell'Olio, and D. Borri, "A Study of Herding Behaviour in Exit Choice during Emergencies based on Random Utility Theory," Saf. Sci., vol. 82, pp. 421-431, 2016.

[27] M. Haghani, M. Sarvi, and Z. Shahhoseini, "Accommodating taste heterogeneity and desired substitution pattern in exit choices of pedestrian crowd evacuees using a mixed nested logit model," J. choice Model., vol. 16, pp. 58-68, 2015.

[28] M. Haghani and M. Sarvi, "Stated and revealed exit choices of pedestrian crowd evacuees," Transp. Res. Part B Methodol., vol. 95, pp. 238-259, 2017.

[29] M. J. Kinsey, E. R. Galea, and P. J. Lawrence, "Stairs or lifts? - A study of human factors associated with lift / elevator usage during evacuations using an online survey," in Pedestrian and Evacuation Dynamics, 2010, pp. 627-636.

[30] K. Andrée, N. Daniel, and E. Joakim, "Evacuation experiments in a virtual reality high-rise building: exit choice and waiting time for evacuation elevators," Fire Mater., 2015.

[31] E. R. Galea, L. Hulse, R. Day, A. Siddiqui, and G. Sharp, "The UK WTC 9/11 evacuation study: an overview of findings derived from first-hand interview data and computer modelling," Fire Mater., vol. 36, no. 5-6, pp. 501-521, 2012.

[32] N. Ding, T. Chen, and H. Zhang, "Experimental Study of Elevator Loading and Unloading Time During Evacuation in High-Rise Buildings," Fire Technol., vol. 53, no. 1, pp. 1-14, 2016. 
[33] L. Dell'Olio, A. Ibeas, and P. Cecin, "The quality of service desired by public transport users," Transp. Policy, vol. 18, no. 1, pp. 217-227, 2011.

[34] Australian Building Codes Board, "Lifts Used During Evacuation," no. 2013, 2013.

[35] NFPA, NFPA 101 Life Safety Code. National Fire Protection Association, Quincy (USA). 2012.

[36] S. Aloi and J. Rogers, "Evacuation and life safety strategies for super high rise buildings," Building for the 21st century: technology, livability, productivity, pp. 429-436, 2001.

[37] S. M. V Gwynne, K. E. Boyce, E. D. Kuligowski, D. Nilsson, A. Robbins, and R. Lovrelgio, "Pros and cons of egress drills," in Interflam 2016, 14th International Conference on Fire Science and Engineering, 2016.

[38] K. A. Notarianni and G. W. Parry, "Uncertainty," in SFPE Handbook of Fire Protection Engineering, Springer, 2016, pp. 2992-3047.

[39] W. J. McGuire, "The nature of attitudes and attitude change," Handb. Soc. Psychol., vol. 3, no. 2, pp. 136-314, 1969.

[40] C. I. Hovland, I. L. Janis, and H. H. Kelley, "Communication and persuasion; psychological studies of opinion change.," New Haven, CT Yale Univ. Press, 1953.

[41] Pathfinder Thunderhead, "Technical Reference," 2017.

[42] M. Hanemann, J. Loomis, and B. Kanninen, "Statistical efficiency of double-bounded dichotomous choice contingent valuation," Am. J. Agric. Econ., vol. 73, no. 4, pp. 1255-1263, 1991.

[43] Y. Cai, I. Deilami, and K. Train, "Customer retention in a competitive power market: Analysis of a'double-bounded plus follow-ups' questionnaire," Energy J., pp. 191-215, 1998.

[44] M. Kinateder, "Social influence in emergency situations-studies in virtual reality," 2013.

[45] E. D. Kuligowski, "Computer evacuation models for buildings," in SFPE Handbook of Fire Protection Engineering, Springer, 2016, pp. 2152-2180.

[46] K. Train, "Halton sequences for mixed logit," Dep. Econ. UCB, 2000.

[47] K. Train and Y. Croissant, "Kenneth Train's exercises using the mlogit package for $R$," $R$, vol. 25, pp. 0-2, 2012.

[48] J. Neyman and E. S. Pearson, "On the problem of the most efficient tests of statistical hypotheses," in Breakthroughs in statistics, Springer, 1992, pp. 73-108. 


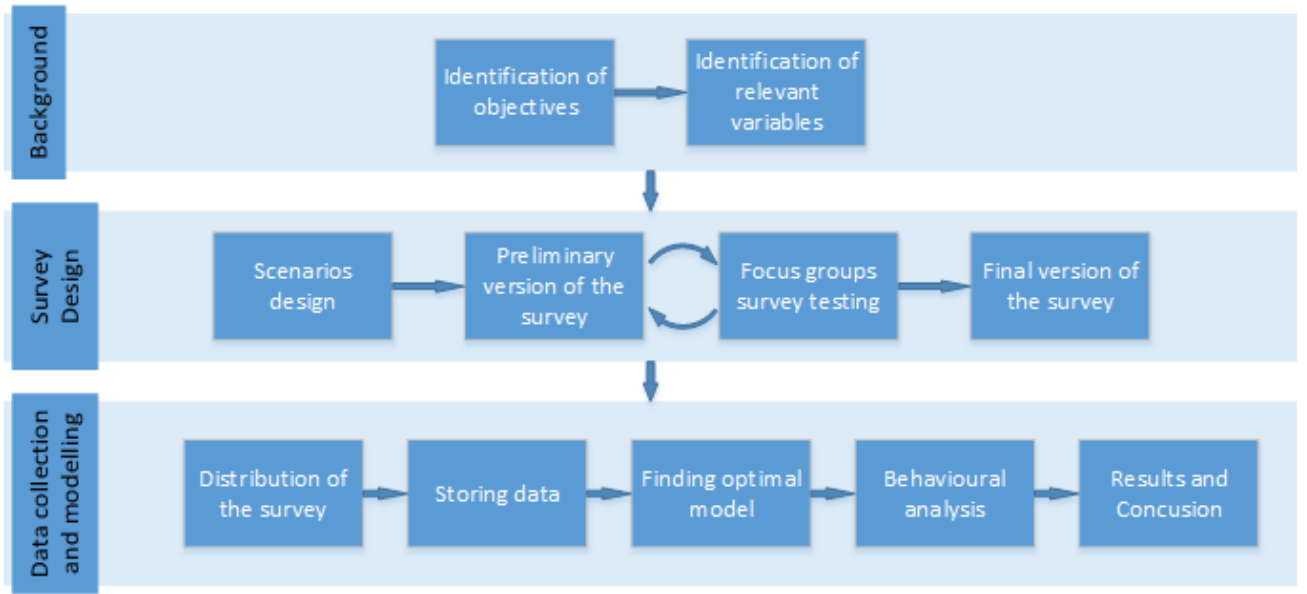

Figure 1. Survey methodological design

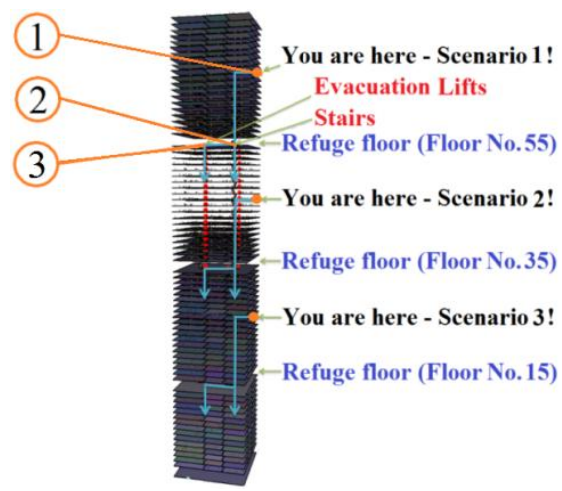

Figure 2. General description of the building evacuation design, scenarios and case studies tested
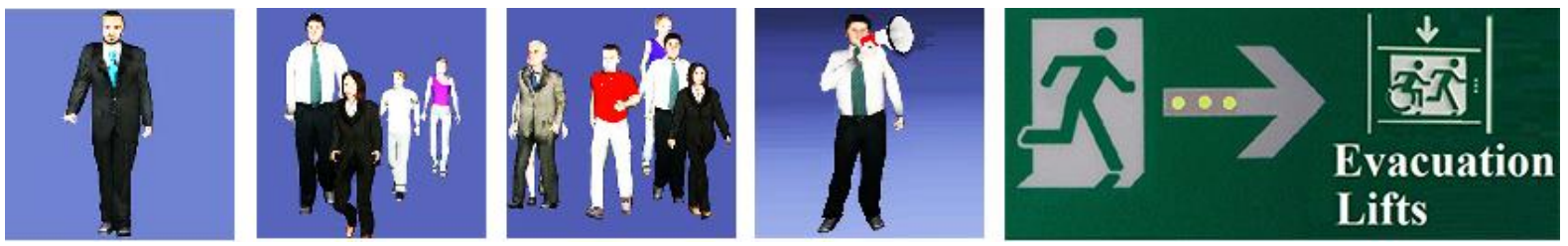

Figure 3. Evacuation scenarios sequentially ordered: going alone, going with family, going with (un)known people, navigated with the help of a responsible person and navigated by dynamic signs
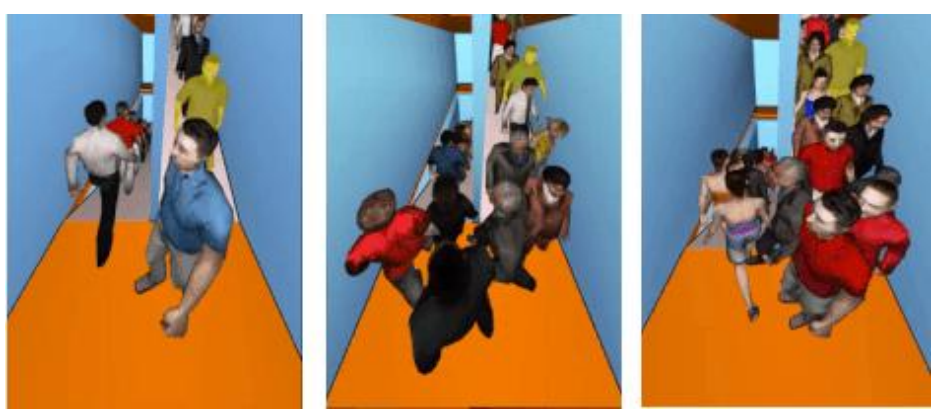

Figure 4. People density on stairs (left - 1 person $/ \mathrm{m}^{2} ;$ middle -2 persons $/ \mathrm{m}^{2}$; right -3 persons $/ \mathrm{m}^{2}$ ). 

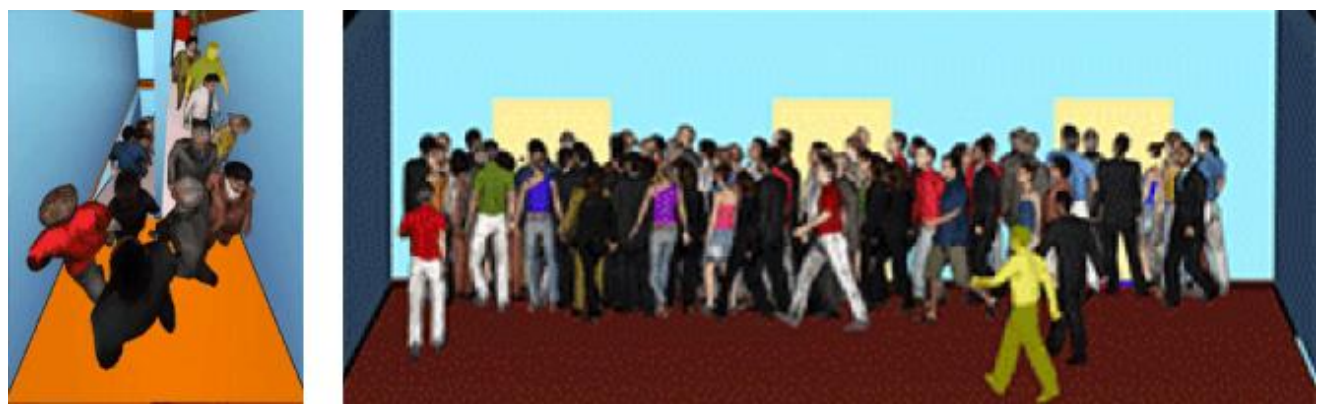

Figure 5. An evacuation scenario considering density on stairs (left -2 persons $/ \mathrm{m}^{2}$ ) and number of people (right -100 people)

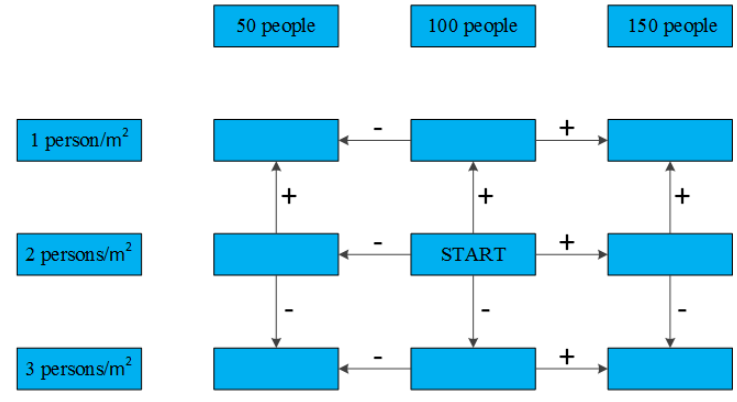

Figure 6. Distribution of scenarios to the participants (+ indicates the next scenario, if evacuation lifts are chosen in the previous scenario; indicates the next scenario, if stairs are chosen in the previous scenario)

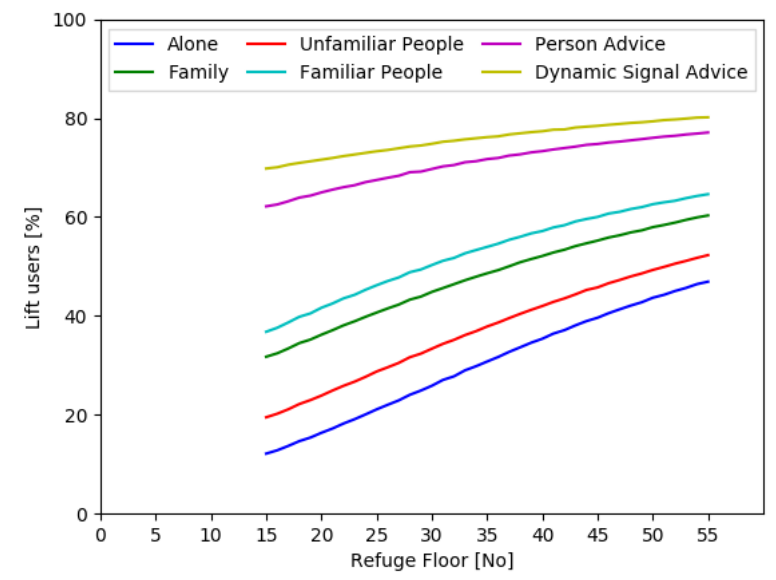

Figure 7. Impact of different scenarios and position of refuge floors on the choice of people to select evacuation lifts for evacuation 

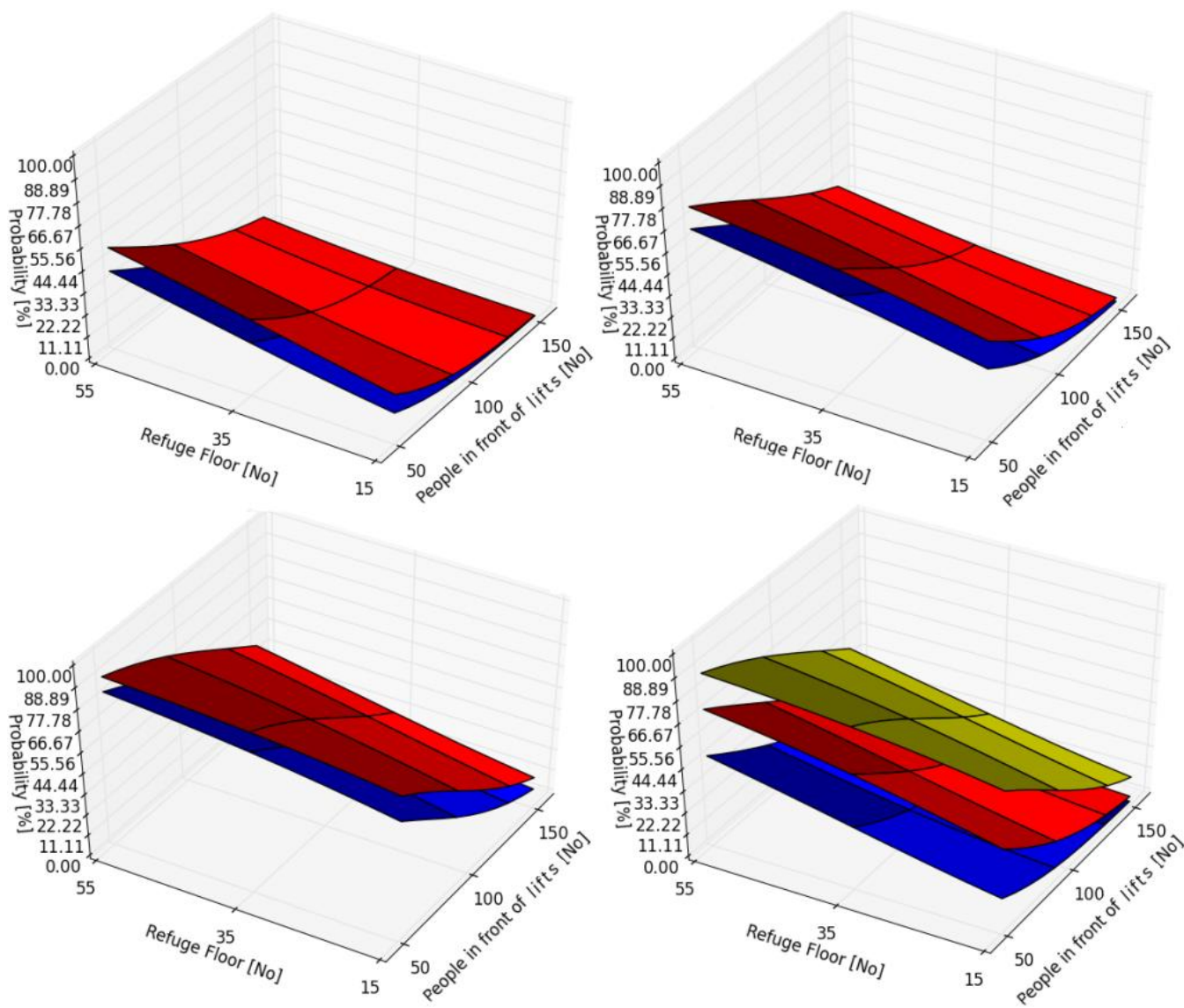

Figure 8. Impact of number of people on stairs, position of refuge floors and people density on stairs on the choice of people to select evacuation lifts for Model 3 (upper left corner -1 person $/ \mathrm{m}^{2}$; upper right corner -2 persons $/ \mathrm{m}^{2}$; lower left corner -3 persons $/ \mathrm{m}^{2}$. Red surface - probability of people who chose to come to refuge floors to wait for evacuation lifts; blue surface - probability of people who decided to proceed via stairs to choose evacuation lifts if they previously decided to go to refuge floors) and for Model 4 (lower right corner) 
Table 1. Chronologically conducted experiments in terms of people choice modelling for evacuation of tall buildings

\begin{tabular}{|c|c|c|c|c|c|c|}
\hline Research & $\begin{array}{l}\text { Data } \\
\text { collection } \\
\text { type }\end{array}$ & $\begin{array}{l}\text { Part } \\
{[\text { No] }}\end{array}$ & $\begin{array}{l}\text { Sociodemographic } \\
\text { characteristics of } \\
\text { participants }\end{array}$ & $\begin{array}{l}\text { Waiting } \\
\text { position } \\
\text { for lifts }\end{array}$ & $\begin{array}{l}\text { Decision-making } \\
\text { questions } \\
\text { evaluated }\end{array}$ & $\begin{array}{l}\text { Parameters considered } \\
\text { for each decision- } \\
\text { making question }\end{array}$ \\
\hline \multirow[t]{2}{*}{ [30] } & $\begin{array}{l}\text { On-site } \\
\text { behavioural } \\
\text { questionnaire }\end{array}$ & 91 & $\begin{array}{l}\text { Mostly students that } \\
\text { live in commercial } \\
\text { buildings, age } 19-25\end{array}$ & \multirow[t]{2}{*}{$\begin{array}{l}\text { Occupant's } \\
\text { floor }\end{array}$} & $\begin{array}{l}\text { Preferred route } \\
\text { choice of escape } \\
\text { route }\end{array}$ & \multirow[t]{2}{*}{ Vertical position of the floor } \\
\hline & Online survey & 229 & Students, age $17-19$ & & $\begin{array}{l}\text { Maximum waiting } \\
\text { time for lifts }\end{array}$ & \\
\hline \multirow[t]{3}{*}{ [26] } & \multirow[t]{3}{*}{$\begin{array}{l}\text { Online } \\
\text { questionnaire }\end{array}$} & \multirow[t]{3}{*}{467} & \multirow{3}{*}{$\begin{array}{l}\text { Mixed participants } \\
\text { (students }(18.9 \%), \\
\text { other professions } \\
(71.9 \%)) \\
\text { Average age } 35 \text { years }\end{array}$} & \multirow[t]{3}{*}{$\begin{array}{l}\text { Occupant's } \\
\text { floor }\end{array}$} & $\begin{array}{l}\text { Preferred choice of } \\
\text { escape route }\end{array}$ & Vertical position of the floor \\
\hline & & & & & $\begin{array}{l}\text { Overcrowding of } \\
\text { lift lobby }\end{array}$ & $\begin{array}{l}\text { Vertical position of the floor } \\
\text { and number of people in } \\
\text { front of lifts }\end{array}$ \\
\hline & & & & & $\begin{array}{l}\text { Maximum waiting } \\
\text { time for lifts }\end{array}$ & $\begin{array}{l}\text { Vertical position of the floor } \\
\text { and age of participants }\end{array}$ \\
\hline \multirow[t]{2}{*}{ [31] } & \multirow{2}{*}{$\begin{array}{l}\text { On-site } \\
\text { behavioural } \\
\text { questionnaire }\end{array}$} & \multirow[t]{2}{*}{573} & \multirow{2}{*}{$\begin{array}{l}\text { People who live, work } \\
\text { and visit high-rise } \\
\text { buildings } \\
\text { Age not available }\end{array}$} & \multirow[t]{2}{*}{$\begin{array}{l}\text { Occupant's } \\
\text { floor }\end{array}$} & $\begin{array}{l}\text { Preferred choice of } \\
\text { escape route }\end{array}$ & \multirow[t]{2}{*}{ Vertical position of the floor } \\
\hline & & & & & $\begin{array}{l}\text { Maximum waiting } \\
\text { time for lifts }\end{array}$ & \\
\hline [27] & $\begin{array}{l}\text { Virtual reality } \\
\text { experiment }\end{array}$ & 72 & $\begin{array}{l}\text { Staff and students; } \\
\text { Average age } 26.5 \text { years }\end{array}$ & Refuge floor & $\begin{array}{l}\text { Maximum waiting } \\
\text { time for lifts }\end{array}$ & $\begin{array}{l}\text { Estimation of the maximum } \\
\text { waiting time }\end{array}$ \\
\hline [29] & Questionnaire & 45 & $\begin{array}{l}\text { Students; } \\
\text { Age 17-23 }\end{array}$ & $\begin{array}{l}\text { Occupant's } \\
\text { floor }\end{array}$ & $\begin{array}{l}\text { Suggested } \\
\text { escaping route }\end{array}$ & Vertical position of the floor \\
\hline \multirow[t]{2}{*}{$\begin{array}{l}\text { This } \\
\text { research }\end{array}$} & \multirow[t]{2}{*}{$\begin{array}{l}\text { Online } \\
\text { questionnaire }\end{array}$} & \multirow[t]{2}{*}{566} & \multirow{2}{*}{$\begin{array}{l}\text { People who work, live, } \\
\text { visit and people who } \\
\text { do not have } \\
\text { connections with high- } \\
\text { rise buildings } \\
\text { Average age } 27.5 \text { years }\end{array}$} & \multirow[t]{2}{*}{ Refuge floor } & $\begin{array}{l}\text { Preferred route } \\
\text { choice and } \\
\text { suggested route } \\
\text { choice }\end{array}$ & $\begin{array}{l}\text { Vertical position of the } \\
\text { floor, messaging strategy } \\
\text { and social influence }\end{array}$ \\
\hline & & & & & $\begin{array}{l}\text { Preferred choice } \\
\text { modelling due to } \\
\text { overcrowding of } \\
\text { lift lobby }\end{array}$ & $\begin{array}{l}\text { Vertical position of the } \\
\text { refuge floor, density on } \\
\text { stairs and number of people } \\
\text { at lift lobby }\end{array}$ \\
\hline
\end{tabular}

Table 2. Description of the scenarios and parameters considered

\begin{tabular}{|c|c|c|c|c|c|c|c|c|}
\hline $\begin{array}{l}\text { Case } \\
\text { study }\end{array}$ & Scenario type & $\begin{array}{l}\text { Scenario } \\
{[\mathrm{No}]}\end{array}$ & $\begin{array}{l}\text { Navigational } \\
\text { strategies }\end{array}$ & $\begin{array}{l}\text { Social } \\
\text { impacts }\end{array}$ & $\begin{array}{l}\text { Refuge } \\
\text { Floors }\end{array}$ & $\begin{array}{l}\text { Density } \\
\text { levels on } \\
\text { stairs }\end{array}$ & $\begin{array}{l}\text { People } \\
\text { levels at } \\
\text { lift lobby }\end{array}$ & Scenario's objective \\
\hline 1 & $\begin{array}{l}\text { Navigational } \\
\text { scenarios } \\
\text { evaluation }\end{array}$ & 18 & 2 & 3 & 3 & - & - & $\begin{array}{l}\text { Testing the difference } \\
\text { between preferred } \\
\text { route choice and } \\
\text { suggested route choice }\end{array}$ \\
\hline 2 & $\begin{array}{l}\text { Choosing lifts } \\
\text { or stairs under } \\
\text { uncertainty }\end{array}$ & 9 & 1 & / & 3 & 3 & - & $\begin{array}{l}\text { Testing the effect of } \\
\text { the density on stair on } \\
\text { preferred route choice }\end{array}$ \\
\hline 3 & $\begin{array}{l}\text { Waiting for lifts } \\
\text { or backing up } \\
\text { to stairs under } \\
\text { uncertainty }\end{array}$ & 27 & 1 & / & 3 & 3 & 3 & $\begin{array}{l}\text { Testing the effect of } \\
\text { the density on stair anc } \\
\text { the number of people } \\
\text { in front of lifts on } \\
\text { preferred route choice }\end{array}$ \\
\hline
\end{tabular}

Table 3. Participants' characteristics

\begin{tabular}{ll}
\hline Characteristics & Results \\
\hline Gender & 303 females; 263 males; \\
Age & $27.5 \pm 5.5$ years \\
Physical activity level & Extremely inactive (1\%); Sedentary (35\%); Moderate active (59\%); Vigorously active (5\%); \\
Height/Weight & $168.24 \pm 18.73 \mathrm{~cm} / 66.76 \pm 16.49 \mathrm{~kg}$ \\
Connection with high-rise buildings & People who work (14\%); live (21\%); visit (34\%); without connection with high-rise buildings (31\%) \\
\hline
\end{tabular}

Table 4. Optimal model estimation for model 1

\begin{tabular}{llll}
\hline Variable & Coefficients & t-value & Significance \\
\hline ASC & 4.4823796 & -15.7442 & $<2.2 \mathrm{e}-16^{* * *}$ \\
Family & -2.8195688 & -13.8956 & $<2.2 \mathrm{e}-16^{* * *}$ \\
UnFamiliarPeople & -1.0669397 & -5.8066 & $6.37 \mathrm{e}-09 * * *$ \\
FamiliarPeople & -3.6923370 & -16.8311 & $<2.2 \mathrm{e}-16^{* * *}$ \\
PersonAdvice & -7.7895786 & -20.4502 & $<2.2 \mathrm{e}-16^{* * *}$ \\
DynamicSignalAdvice & -10.898725 & -13.9566 & $<2.2 \mathrm{e}-16^{* * *}$
\end{tabular}




\section{RefugeFloor}

BMI*FitnessLevel*Concern

KnowingThatLiftsCannotBeUsed

SaferByStair

QuickerByStair

EscapingCrowdInFrontOfLifts

Standard deviation of parameter distribution

Sd ASC

Sd Family

Sd UnFamiliarPeople

Sd FamiliarPeople

Sd PersonAdvice

Sd DynamicSignalAdvice

Sd RefugeFloor

Sd BMI*FitnessLevel*Concern

Sd KnowingThatLiftsCannotBeUsed

Sd SaferByStair

Sd QuickerByStair

Sd EscapingCrowdInFrontOfLifts

$\begin{array}{lll}-0.0844818 & -15.6565 & <2.2 \mathrm{e}-16^{* * *} \\ -0.0392098 & -12.5941 & <2.2 \mathrm{e}-16^{* * *} \\ 0.7101657 & 5.5924 & 2.24 \mathrm{e}-08 * * * \\ 1.9468786 & 13.0599 & <2.2 \mathrm{e}-16^{* * *} \\ 1.1502334 & 7.9267 & 2.22 \mathrm{e}-15 * * * \\ 0.7175469 & 5.8086 & 6.30 \mathrm{e}-09 * * *\end{array}$

$\begin{array}{lll}2.8764739 & 18.1883 & <2.2 \mathrm{e}-16^{* * *} \\ 2.9317776 & 12.4490 & <2.2 \mathrm{e}-16^{* * *} \\ 1.9552166 & -9.2203 & <2.2 \mathrm{e}-16^{* * *} \\ 2.2270202 & -9.3397 & <2.2 \mathrm{e}-16^{* * *} \\ 5.5154392 & 15.4930 & <2.2 \mathrm{e}-16^{* * *} \\ 9.1141055 & 11.7698 & <2.2 \mathrm{e}-16^{* * *} \\ 0.1258769 & 21.1707 & <2.2 \mathrm{e}-16^{* * *} \\ 0.0243007 & 6.5207 & 7.00 \mathrm{e}-11 * * * \\ 1.1714130 & 7.1682 & 7.60 \mathrm{e}-13^{* * *} \\ 2.3883402 & 13.1568 & <2.2 \mathrm{e}-16^{* * *} \\ 1.1195836 & 5.3483 & 8.88 \mathrm{e}-08 * * * \\ 0.6771840 & 3.9865 & 6.71 \mathrm{e}-05 * * *\end{array}$

Log-likelihood: -3390 McFadden $\mathrm{R}^{2}: 0.4843$

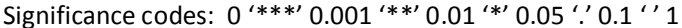

Table 5. Impact of a specific scenario and refuge floors' position on a person's choice - Model 1

\begin{tabular}{llll}
\hline $\mathbf{P}_{\text {lifts }}(\%)$ & $\mathbf{P}_{\text {stairs }}(\%)$ & Scenario & Refuge Floor \\
\hline 12.18 & 87.82 & 1 & 15 \\
31.75 & 68.25 & 2 & 15 \\
19.46 & 80.54 & 3 & 15 \\
26.86 & 63.14 & 4 & 15 \\
62.09 & 37.91 & 5 & 15 \\
69.85 & 30.15 & 6 & 15 \\
30.80 & 69.20 & 1 & 35 \\
48.60 & 51.40 & 2 & 35 \\
37.82 & 62.18 & 3 & 35 \\
53.97 & 46.03 & 4 & 35 \\
71.73 & 28.27 & 5 & 35 \\
76.22 & 23.78 & 6 & 35 \\
47.08 & 52.92 & 1 & 55 \\
60.24 & 39.76 & 2 & 55 \\
52.30 & 47.70 & 3 & 55 \\
64.54 & 35.46 & 4 & 55 \\
77.12 & 22.88 & 5 & 55 \\
80.24 & 19.76 & 6 & 55 \\
\hline
\end{tabular}

Table 6. Optimal model estimation for model 2

\begin{tabular}{llll}
\hline Variable & Coefficients & t-value & Significance \\
\hline ASC & 9.2729350 & -16.4520 & $<2.2 \mathrm{e}-16^{* * *}$ \\
RefugeFloor & -0.0829599 & -12.8155 & $<2.2 \mathrm{e}-16^{* * *}$ \\
DensityStair & -3.3389129 & -17.1268 & $<2.2 \mathrm{e}-16^{* * *}$ \\
BMI*FitnessLevel*Concern & -0.0387135 & -10.1021 & $<2.2 \mathrm{e}-16^{* * *}$ \\
KnowingThatLiftsCannotBeUsed & 1.4089045 & 7.7436 & $9.77 \mathrm{e}-15^{* * *}$ \\
SaferByStair & 1.8567131 & 10.2127 & $<2.2 \mathrm{e}-16^{* * *}$ \\
QuickerByLifts & -1.8974230 & -9.7922 & $<2.2 \mathrm{e}-16^{* * * *}$ \\
& & & \\
Standard deviation of parameter distribution & & & $<2.2 \mathrm{e}-16^{* * *}$ \\
Sd ASC & 2.5984119 & -11.1054 & $<2.2 \mathrm{e}-16^{* * *}$ \\
Sd RefugeFloor & 0.0627389 & 12.2521 & $<2.2 \mathrm{e}-16^{* * *}$ \\
Sd DensityStair & 1.9067433 & 14.7561 & $<2.2 \mathrm{e}-16^{* * *}$ \\
Sd BMI*FitnessLevel ${ }^{*}$ Concern & 0.0515362 & 8.7910 & $1.41 \mathrm{e}-08 * * *$ \\
Sd KnowingThatLiftsCannotBeUsed & 1.9228649 & -5.6725 & $5.69 \mathrm{e}-05^{* * *}$ \\
Sd SaferByStair & 1.4077972 & -4.0252 & $2.86 \mathrm{e}-07^{* * * *}$ \\
Sd QuickerByLifts & 1.6129036 & 5.1322 & \\
Log-likelihood: -1920.4 & McFadden $\mathrm{R}^{2}: 0.44712$ & $\operatorname{Pr}(>C h i s q): 0.1314$ & \\
\hline
\end{tabular}




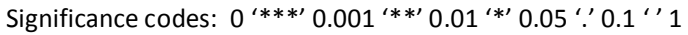

Table 7. Optimal model estimation for model 3, and model 4 which is presented inside the brackets

\begin{tabular}{|c|c|c|c|}
\hline Variable & Coefficients & t-value & Significance \\
\hline ASC & $2.5521112(4.0060057)$ & $-12.8228(-22.157)$ & $<2.2 \mathrm{e}-16^{* * *}\left(2.2 \mathrm{e}-16^{* * *}\right)$ \\
\hline RefugeFloor & $-0.0566272(-0.0672735)$ & $-22.2758(-27.104)$ & $<2.2 \mathrm{e}-16^{* * *}\left(2.2 \mathrm{e}-16^{* * *}\right)$ \\
\hline DensityStair & $-2.3083952(-2.5801772)$ & $-30.3871(-33.999)$ & $<2.2 \mathrm{e}-16^{* * *}\left(2.2 \mathrm{e}-16^{* * *}\right)$ \\
\hline PeopleLift & $0.0577420(0.0578643)$ & $38.6730(39.261)$ & $<2.2 \mathrm{e}-16^{* * *}\left(2.2 \mathrm{e}-16^{* * *}\right)$ \\
\hline PreviousChoice & $1.2036380(-)$ & $14.1312(-)$ & $<2.2 \mathrm{e}-16^{* * *}(-)$ \\
\hline \multicolumn{4}{|c|}{$\begin{array}{l}\text { Standard deviation of } \\
\text { parameter distribution }\end{array}$} \\
\hline Sd ASC & $2.5236671(2.7850064)$ & $31.6997(34.158)$ & $<2.2 \mathrm{e}-16^{* * *}\left(2.2 \mathrm{e}-16^{* * *}\right)$ \\
\hline Sd RefugeFloor & $0.0448023(0.0507037)$ & $22.7431(25.721)$ & $<2.2 \mathrm{e}-16^{* * *}\left(2.2 \mathrm{e}-16^{* * *}\right)$ \\
\hline Sd DensityStair & $0.3050072(0.3249319)$ & $5.8499(6.627)$ & $4.919 \mathrm{e}-09 * * *(3.426 \mathrm{e}-11 * * *)$ \\
\hline Sd PreviousChoice & $0.6976872(-)$ & $3.8614(-)$ & $0.0001127^{* * *}(-)$ \\
\hline
\end{tabular}

Table 8. Impact of density of people on stairs, the position of refuge floors and the number of people in front of lifts on occupant's choice to choose lifts for evacuation - Model 3 and Model 4

\begin{tabular}{|c|c|c|c|c|}
\hline$P_{\text {lifts }}(\%)$ - Model 3 & $P_{\text {lifts }}(\%)$ - Model 4 & Number of People & Density [persons/m²] & Refuge Floor \\
\hline 23.52 & 16.52 & 50 & 1 & 15 \\
\hline 5.24 & 3.51 & 100 & 1 & 15 \\
\hline 0.65 & 0.44 & 150 & 1 & 15 \\
\hline 50.34 & 41.59 & 50 & 2 & 15 \\
\hline 18.62 & 14.68 & 100 & 2 & 15 \\
\hline 3.79 & 3.04 & 150 & 2 & 15 \\
\hline 76.19 & 70.05 & 50 & 3 & 15 \\
\hline 43.32 & 38.33 & 100 & 3 & 15 \\
\hline 14.74 & 13.21 & 150 & 3 & 15 \\
\hline 37.01 & 30.07 & 50 & 1 & 35 \\
\hline 12.27 & 9.87 & 100 & 1 & 35 \\
\hline 2.41 & 2.04 & 150 & 1 & 35 \\
\hline 62.97 & 56.44 & 50 & 2 & 35 \\
\hline 31.11 & 27.43 & 100 & 2 & 35 \\
\hline 9.48 & 8.75 & 150 & 2 & 35 \\
\hline 83.38 & 79.54 & 50 & 3 & 35 \\
\hline 56.48 & 53.11 & 100 & 3 & 35 \\
\hline 25.93 & 25.17 & 150 & 3 & 35 \\
\hline 49.83 & 44.30 & 50 & 1 & 55 \\
\hline 23.16 & 20.90 & 100 & 1 & 55 \\
\hline 7.24 & 7.01 & 150 & 1 & 55 \\
\hline 71.68 & 67.31 & 50 & 2 & 55 \\
\hline 44.07 & 41.57 & 100 & 2 & 55 \\
\hline 19.18 & 19.09 & 150 & 2 & 55 \\
\hline 87.14 & 84.70 & 50 & 3 & 55 \\
\hline 66.38 & 64.50 & 100 & 3 & 55 \\
\hline 38.60 & 38.93 & 150 & 3 & 55 \\
\hline
\end{tabular}


Table 9. Percentage of people selecting a particular reason for choosing stairs or evacuation lifts for evacuation from tall buildings

\begin{tabular}{llll}
\hline Reasons for choosing stairs & Refuge Floor & & 35th floor \\
\hline & 15th floor & 35th \\
\cline { 2 - 4 } Safer way & 73.5 & 51.6 & 45.9 \\
Quicker way & 48.6 & 20 & 9.5 \\
Escaping crowd in front of lifts & 51.9 & 48.4 & 40.3 \\
Knowing that lifts cannot be used for evacuation & 62.9 & 57.8 & 54.8 \\
Allow others to use lifts & 32.7 & 26.5 & 23.3 \\
Concerns about waiting time for lifts & 53.4 & 49.1 & 45.4 \\
Concern about the programming of the lifts & 31.4 & 36.4 & 32.7 \\
Greater Level of control using stairs & 47 & 41.5 & 36 \\
\hline Reasons for choosing lifts & & & 20.8 \\
\hline Safer way & 4.8 & 15.5 & 68.4 \\
Quicker way & 28.6 & 54.2 & 3.3 \\
Escaping crowd from stairs & 46.1 & 49.6 & 38 \\
Concern about physical fitness & 16.4 & 27.2 \\
Greater Level of control using lifts & 7.9 & 7.4 \\
\hline
\end{tabular}




\section{University Library}

\section{- M M N E R VA A gateway to Melbourne's research publications}

Minerva Access is the Institutional Repository of The University of Melbourne

Author/s:

Aleksandrov, M;Rajabifard, A;Kalantari, M;Lovreglio, R;Gonzalez, VA

Title:

People Choice Modelling for Evacuation of Tall Buildings

Date:

2018-09-01

Citation:

Aleksandrov, M., Rajabifard, A., Kalantari, M., Lovreglio, R. \& Gonzalez, V. A. (2018).

People Choice Modelling for Evacuation of Tall Buildings. FIRE TECHNOLOGY, 54 (5), pp.1171-1193. https://doi.org/10.1007/s10694-018-0731-1.

Persistent Link:

http://hdl.handle.net/11343/282810 